International Journal of Medical Sciences

ISSN 1449-1907 www.medsci.org 2008 5(3):106-112

Research Paper

(C) Ivyspring International Publisher. All rights reserved

\title{
Breast cancer screening in France: results of the EDIFICE survey
}

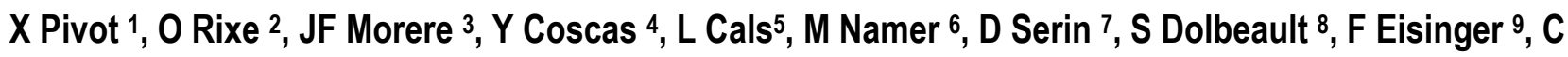 \\ Roussel ${ }^{10}$, JY Blay ${ }^{11}$
}

1. University Hospital Jean Minjoz, INSERM UMR 845, Besancon, France

2. University Hospital of Pitier Salpetriere, Paris France

3. University Hospital of Avicenne, Bobigny, France

4. Porte de Saint Cloud center, Boulogne Billancourt, France

5. Font-Pre Hospital, Toulon, France

6. Azureen cancer center, Mougins, France

7. Saint Catherine Institut, Avignon, France

8. Curie cancer center, Paris, France

9. Paoli Calmettes Institut, INSERM UMR 599, Marseille, France

10. Roche Affiliate, Paris, France

11. Leon Berrad anti cancer center Lyon, France

Correspondence to: Professor Xavier Pivot, Centre Hospitalier Universitaire de Besançon, Service d'Oncologie Médicale, 25030 BESANCON cedex, France. Phone: +33 (0)3 816688 58; Fax: +33 (0)2 816688 58; Email: Xavier.pivot@univ-fcomte.fr

Received: 2008.03.13; Accepted: 2008.05.23; Published: 2008.05.24

Background: The EDIFICE survey aimed to investigate the compliance of the general population to the screening tests available in France for the 4 most common cancers: breast, colorectal, prostate and lung. Implementation of breast cancer screening has been generalized in France since 2003: women aged between 50 and 74 years are systematically invited to perform a mammography every second year. Results pertaining to breast cancer are reported hereafter.

Methods: This nationwide observational survey was carried out in France from 18 January to 2 February 2005 among representative samples of 773 women aged between 40 and 75 years and 600 general practitioners (GPs). Information collected included socio-demographic characteristics, attitude towards cancer screening and actual experience of cancer screening, as well as GPs' practice regarding screening. The precision of the results is $\pm 4.3 \%$ for a $95 \%$ confidence interval.

Results: Among the 507 participating women aged between 50 and 74 years, 92.5\% (469/507) had undergone at least one mammography: $54.6 \%(256 / 469)$ underwent this test on their own initiative and $44.6 \%(209 / 469)$ of women performed it in the framework of a systematic screening plan. Most women participating in the systematic screening $(89.0 \%$ i.e. $186 / 209)$ had a mammography within the last dating from less than 2 years versus $73.8 \%(189 / 256)$ of those who performed it outside the screening program (Chi ${ }^{2}$ test; $\left.\mathrm{p}<0.01\right)$. Interestingly, 422 women (61.9\% i.e. $422 / 682$ women aged between $40-75$ years with at least one mammography) had performed a mammography before the recommended age for screening. There was a significant correlation $(p=0.009)$ between the existence of a first mammography before 50 years of age and subsequent screening on women's own initiative (54.6\% of 469 screened women). Main reasons for not performing the screening test every second year (77 women aged between 50-74 years) included: feeling unconcerned and/or unmotivated $(p=0.0001)$, no cancer anxiety $(\mathrm{p}=0.020)$ and no recommendation by the GP $(\mathrm{p}=0.015)$; Of the 600 participating GPs, $68.6 \%(412 / 600)$ systematically recommended a mammography to their patients. GPs' perceptions of the reasons for women's avoidance of the screening test were unwillingness to be aware of mammography results $(44.4 \%-266 / 600)$ and the belief that mammography was painful $(52.5 \%$ - 315/600).

Conclusion: The main result of the EDIFICE survey is the high rate of women's attendance at mammography screening. The EDIFICE survey pointed out that systematic and organized screening played a major role in the regularity of screening tests for breast cancer every second year. GPs and gynaecologist are key actors in heightening public awareness.

Key words: Breast cancer, screening, Survey, mammography

\section{Introduction}

The EDIFICE survey is the first study focusing on the compliance of French population adherence and general practitioners' attitude towards cancer screening for the four commonest cancers: breast, colorectal, prostate and lung cancers. The hierarchy of cancer screening recommendation established by USPSTF (U.S. Preventive Services Task Force) supports a systematic screening for breast cancer [1]. In France, biennial mammography screening has been proposed to women older than 50 years since 1989 in pilot areas, 
and over the whole country since 2003, based on one mammography every second year for every woman aged between 50 and 74 years [2]. Its worth to stress that in France, when a woman undergone a mammography outside the national screening program she will be reimburse by the national health insurance. The EDIFICE nationwide survey collected data at the national level (the level of funding) about citizens/consumers' accessibility to available cancer screening procedures (through organized programs or individual initiatives) and general practitioners' (GPs) behaviour towards cancer screening [3]. The EDIFICE results pertaining to breast cancer are reported hereafter.

\section{Methods}

\section{General Population survey}

EDIFICE was carried out by telephone from January $18^{\text {th }}$ to February $2^{\text {nd }}, 2005$ among a representative sample of subjects living in France and aged between 40 and 75 years. Representativeness of the survey sample for sex, age, profession and double stratification by geographical area and community size as compared to the French general population was ensured by the use of the method of quotas, based on the statistics of the French Employment Survey conducted in 2002 by the French National Institute for Statistics and Economical Studies (INSEE) [4,5]. The 170-item survey questionnaire was administered by trained and independent interviewers of TNS-Healthcare SOFRES Institute using the Computer-Assisted Telephone Interview (CATI) technique. Telephone interviews lasted 25 minutes on average. The survey questionnaire collected information about subjects' socio-demographic characteristics (gender, age, region of residence, community size), attitude and behaviour regarding cancer screening (in general and for the organs concerned), actual experience of cancer screening, and attitude as regards personal health (self-medication, medical consultation during the past year, tobacco and alcohol consumption). For a given screening test, the questionnaire distinguished tests performed for screening purpose and those performed following symptoms. A main sample of 1509 subjects aged between 40 and 75 years was interviewed. An additional sample of 100 subjects aged between 50 and 74 years (recommended age interval for the screening of colorectal cancer) was also interviewed in order to obtain a sufficient number of subjects living in the departments of France involved in planned screening of colorectal cancer [6]. Computerized weighting of the whole sample of 1609 subjects allowed for compensation of under-representation of the additional sample (adjustment to the proportion of all subjects living in the 22 departments of France involved in organized colorectal cancer screening programs). Subjects with a personal history of cancer $(\mathrm{N}=105)$ were excluded from analysis because actual experience of cancer might affect cancer screening perceptions.

Therefore, the whole subject sample included 1504 individuals aged between 40 and 75 years, among whom 773 women. A subset of 507 women was aged between 50 and 74 years old, they are targeted by the national implemented screening which systematically invites those women to perform a mammography every two year. Additional sample of 255 women (younger than 50 years old) who are not invited in the systematic screening were not included in the present analysis.

\section{Survey among General Practitioners}

A nationwide observational survey was carried out by telephone from January $31^{\text {st }}$ to February $18^{\text {th }}$, 2005 among a representative sample of general practitioners (GPs) practicing in France. Representativeness of the survey sample for age and region of residence (five regions) as compared to the national population of GPs was ensured by the use of the method of quotas ${ }^{3}$. Trained and independent interviewers of TNS-Healthcare SOFRES Institute using the Computer-Assisted Telephone Interview (CATI) technique administered the survey questionnaire. The 45-item survey questionnaire collected information about GPs' socio-demographic characteristics (gender, age, department of France) and their medical practice regarding screening of cancer (breast, colorectal, prostate, and lung cancer), especially perceptions on screening methods, level of screening counselling, type of screening tests recommended, perception of obstacles to screening, and patients' expectations about cancer screening according to GPs. A total number of 600 GPs were interviewed.

\section{Statistic analysis}

This survey had been realized through phone call according to the quota methods. In worth case, the precision of the results was $\pm 4.3 \%$ for a $95 \%$ confidence interval in the 507 women eligible in the national French screening plan. The precision of the result for the GP's survey was $+/-4 \%$ for a $95 \%$ confidence interval in the 600 GP Data analyses was essentially descriptive. Quantitative data were described by the means and standard deviations (SD) and categorical data by the numbers in each category and corresponding percentages. Comparison of distribution according to women behavior were 
carried out by the Student's $t$ test for quantitative data, and by the $Z$ test and the Chi-square test for the comparison of percentages and numbers, respectively, in the case of categorical data. Differences were considered statistically significant when the probability value was less than 0.05 (bilateral test). Search of factors explaining the behaviour to perform a breast cancer screening and the risk to withdraw over the time has been done by logistic regression. Multivariate logistic regression analyses were expressed in terms of odd ratio (OR) and 95\% confidence interval (CI) and performed using the SAS ${ }^{\circledR}$ software, version 8.2 (proc FREQ and proc LOGISTIC procedures).

\section{Results}

Characteristics of all the 773 women questioned in the survey are summarized in table 1. Among these women 507 were aged between 50 to 74 years old and targeted by the national screening program. Their characteristics are listed in table $\mathbf{1 .}$

Table 1: Main characteristics of participating women

\begin{tabular}{|c|c|c|}
\hline & $\begin{array}{l}\text { Women aged } \\
\text { between } 50 \text { and } \\
74 \text { years old } \\
(\mathrm{n}=507)\end{array}$ & $\begin{array}{c}\text { Women aged } \\
\text { between } 40 \text { and } \\
75 \text { years old } \\
(n=773)\end{array}$ \\
\hline $\begin{array}{l}\text { Mean age (standard } \\
\text { deviation) }\end{array}$ & $60.9( \pm 7.2)$ years & $55.7( \pm 10.0)$ years \\
\hline \multicolumn{3}{|l|}{ Community size: } \\
\hline - countryside & $25.0 \%$ & $26.3 \%$ \\
\hline $\begin{array}{l}\text { - town including } 2000 \text { to } \\
100000 \text { inhabitants }\end{array}$ & $33.1 \%$ & $31.2 \%$ \\
\hline $\begin{array}{l}\text { - town including }>100000 \\
\text { inhabitants }\end{array}$ & $41.9 \%$ & $42.5 \%$ \\
\hline \multicolumn{3}{|l|}{ France areas : } \\
\hline - Paris & $17.9 \%$ & $17.8 \%$ \\
\hline - West & $23.4 \%$ & $23.3 \%$ \\
\hline - North-East & $23.7 \%$ & $24.1 \%$ \\
\hline - South-West & $9.2 \%$ & $9.9 \%$ \\
\hline - South-East & $25.8 \%$ & $24.9 \%$ \\
\hline \multicolumn{3}{|l|}{ Marital status: } \\
\hline married / cohabitation & $69.0 \%$ & $72.2 \%$ \\
\hline single & $5.3 \%$ & $6.4 \%$ \\
\hline divorced / widowed & $25.7 \%$ & $21.4 \%$ \\
\hline \multicolumn{3}{|l|}{ Study levels: } \\
\hline $\begin{array}{l}\text { at least school certificate }+ \\
2 y\end{array}$ & $18.7 \%$ & $22.2 \%$ \\
\hline secondary school & $47.2 \%$ & $53.1 \%$ \\
\hline primary school & $30.4 \%$ & $21.5 \%$ \\
\hline no study & $3.7 \%$ & $3.2 \%$ \\
\hline Smoker* & $14.5 \%$ & $21.0 \%$ \\
\hline Alcohol consumer** & $46.7 \%$ & $45.2 \%$ \\
\hline $\begin{array}{l}\text { Consultation with a } \\
\text { physician during the } 12 \\
\text { last months }\end{array}$ & $90.7 \%$ & $88.7 \%$ \\
\hline $\begin{array}{l}\text { Consultation with a } \\
\text { psychiatrist or } \\
\text { psychologue or } \\
\text { psychotropes treatment }\end{array}$ & $40.4 \%$ & $38.2 \%$ \\
\hline
\end{tabular}

Survey among women with 50 to 74 years old

A total of $92.5 \%(469 / 507)$ of this targeted population declared to have undergone at least one mammography (figure 1). The significant characteristics found by the univariate analysis in the subset of women who never declared performing a screening test in comparison with the rest of women, were the following: age beyond 70 years old $(\mathrm{p}=$ $0.0003)$, low social-professional level $(p=0.000004)$, low educational level $(\mathrm{p}=0.021)$, single $(\mathrm{p}=0.014)$. Those women who never declared performing a screening test were significantly less anxious concerning health $(\mathrm{p}=0.023)$, they were afraid of medical and screening tests $(p=0.015)$, they had less often than other a medical physical exam $(p=0.011)$ or a gynaecologic exam $(p=0.000000 \ldots)$, they feel less motivated or less concerned by screening ( $\mathrm{p}=$ $0.000000 \ldots)$. In the multivariate analysis, the following significant factors were linked with no-screening attendance: age younger than 54 years old and widowed/divorced status (adjusted OR $=0.11$ and 0.32 , respectively). The major factors related to the realization of a screening mammography were: consultation within the last 12 months by a GP (adjusted $\mathrm{OR}=3.19$ ) or a gynaecologist (adjusted $\mathrm{OR}=$ 10.23) and feeling motivate to undergo a breast cancer screening (adjusted OR $=7.71$ ). The Figure 2 summarizes the results.

Survey among women with 50 to 74 years old who declared performing at least one mammography

Among the 469 women who had undergone a mammography, $54.6 \%(256 / 469)$ underwent this test on their own initiative as an individual screening and $44.6 \%(209 / 469)$ of women performed it in the framework of a systematic screening plan (figure 1). The participation to organized screening programs for breast cancer increased with the age of the local program: from $30.0 \%(70 / 233)$ in areas where the program was set up in 2003 to $64.6 \%$ (82/127) in those where organized programs were initiated between 1989 and 1996 ( $\mathrm{p}=0.0000000004$ ) (figure 3). The individual who performed inside the national screening program was significantly lower between 50 and 54 years old than in the other subgroup of age $(\mathrm{p}=$ $0.022-$ CHI2) (figure 4). A total of 422 women (61.9\% $422 / 682$ ) had performed a mammography before the recommended age for screening. There was a significant relationship $(\mathrm{p}=0.009)$ between the existence of a first mammography before 50 years old and subsequent screening based on women's outside the organized national screening program $(54,6 \%$ of 469 - 256/469 screened women). 

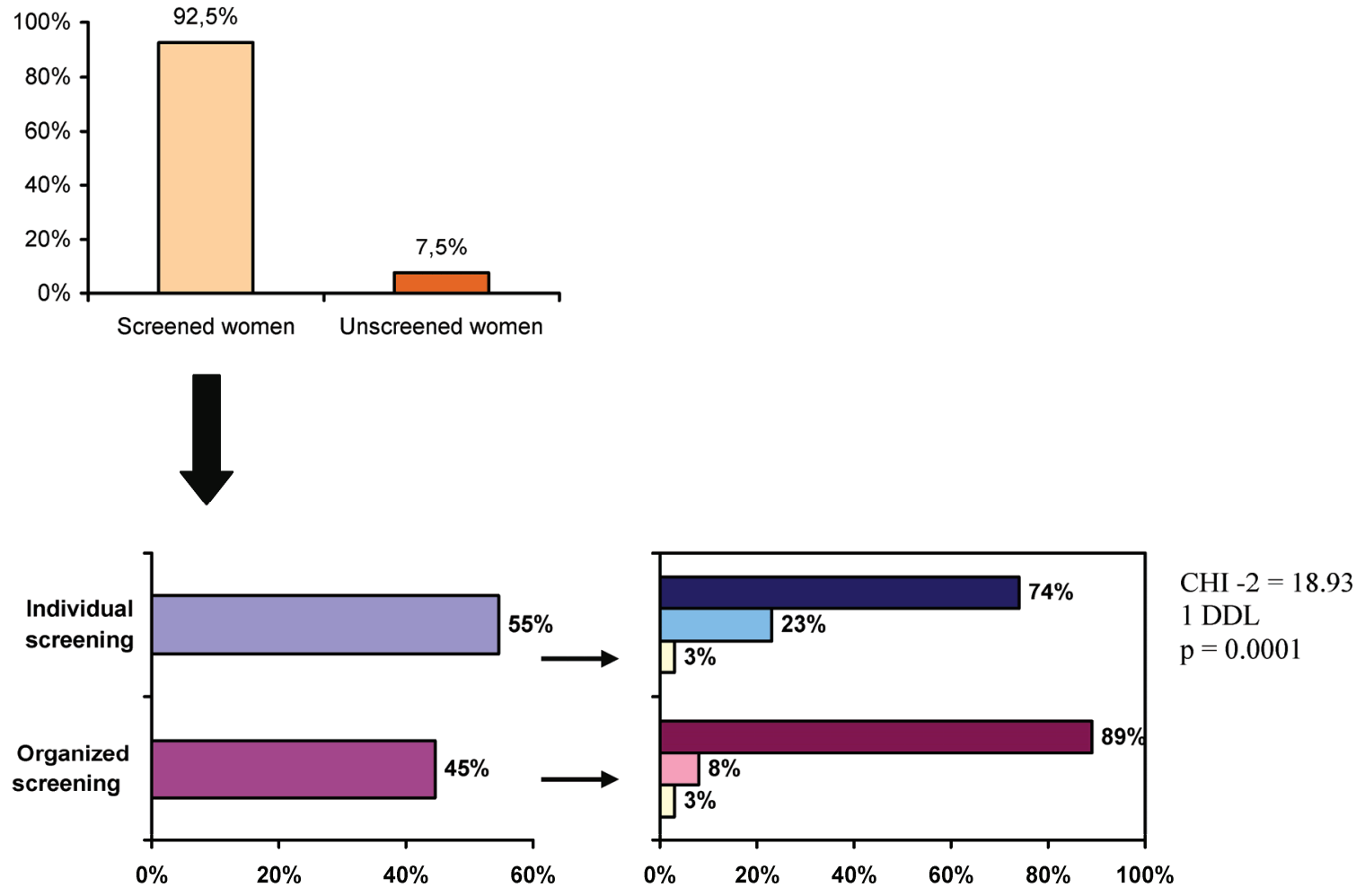

469 women between $50-74$ years old who had declared a screening test.

* At least one mammography within the framework of organized screening.

** Mammographies only within the framework of individual screening.

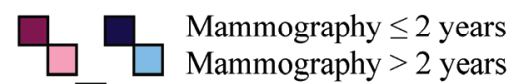

Figure 1: Influence of organization on breast cancer screening.

Consultation of a gynecologist

in the last 12 months

Feeling motivated/ready to undergo

breast cancer screening

Consultation of a GP

in the last 12 months

Status: widowed

Aged 50-54 years

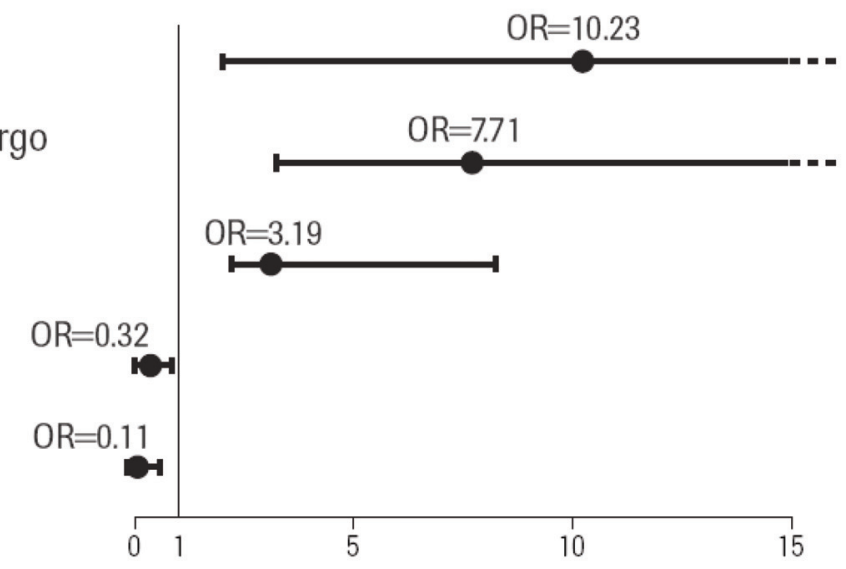

\section{Factors impeding breast cancer screening Factors promoting breast cancer screening}

Note: The following variables were tested in the multivariate analysis: socio-demographic factors (younger than 70 years old, married / cohabitation, superior school level, high social-professional status), behaviors toward health care (anxious related to health, GP consultation within the last 12 months, gynaecologist consultation within the last 12 months), own perception of screening (feeling concerned, feeling motivated, screening result increase chance to cure), anxious factors (breast cancer anxiety, screening test anxiety), cancer in surrounding (all cancer, breast cancer).

Figure 2: Multivariate analysis of the main reasons for performing or not breast cancer screening. 


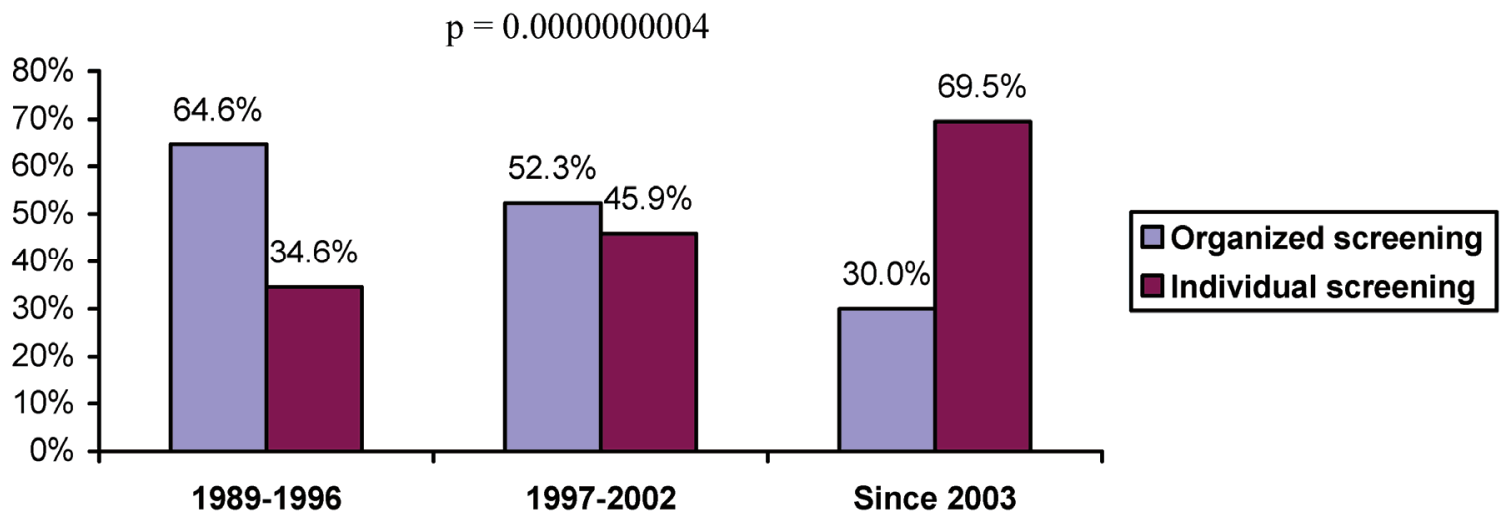

$\mathrm{CHI}-2=43.48,2$ DDL.

Figure 3: Date of breast cancer screening implementation and observed screening rate.

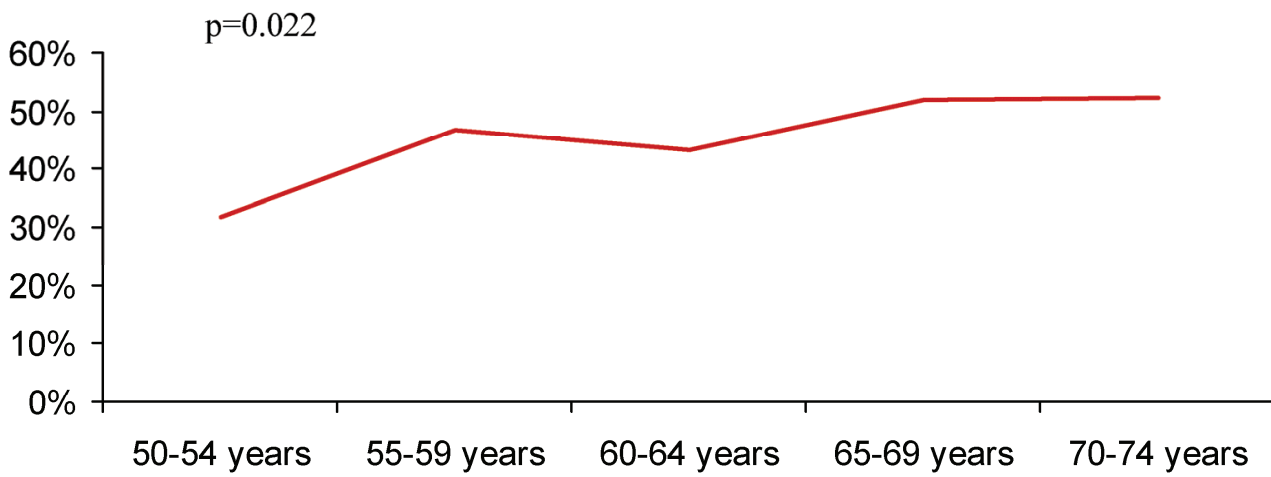

Organized screening

$\mathrm{CHI}-2=11.42,4 \mathrm{DDL}$

Figure 4: Organized Breast cancer screening according to the age.

\section{Biennial mammography compliance survey among women 50 to 74 years old}

Among the women who declared to have undergone at least one mammography between 50 and 74 years old, $15.2 \%(77 / 507)$ did not repeat this test according to the recommended rhythm of screening test, every 2 years: $19.5 \%$ (15/77) stopped screening after the first mammography and $80.5 \%(62 / 77)$ after several mammographies. The factors related to this lack of compliance were: age older than 65 years old ( $p$ $=0.007)$, single $(p=0.001)$, low socio-professional levels $(p<0.006)$, GPs at the origin of the first mammography $(p=0.015)$, gynecologist consultation lasting from more than 12 months ( $p=0.000000 \ldots)$; Main significant reasons for not performing the screening test every 2 years were: feeling unconcerned and/or unmotivated $(\mathrm{p}=0.0001)$, no cancer anxiety $(\mathrm{p}=0.020)$ and no recommendation by the GP $(\mathrm{p}=0.015)$. A proportion of $89.0 \%(186 / 209)$ of women who participated in the national systematic screening plan had a mammography dating from less than 2 years versus $73.9 \%(189 / 256)$ of those who performed it as a voluntary move $(p=0.000008)$ (Figure 1$)$. In the multivariate analysis, the remained significant factors which increase the probability to performed a mammography within the recommended interval were (Figure 5): involvement in national screening (adjusted OR: 0.19), breast cancer anxiety (adjusted OR: 0.51), gynecologist consultation within last 12 months (adjusted OR: 0.12), non unpleasant perception of the previous mammography (adjusted OR: 0.49). In contrast the existence of clinical abnormality related to the first mammography decreased the probability to perform the screening every 2 years (adjusted OR: 2.90). 


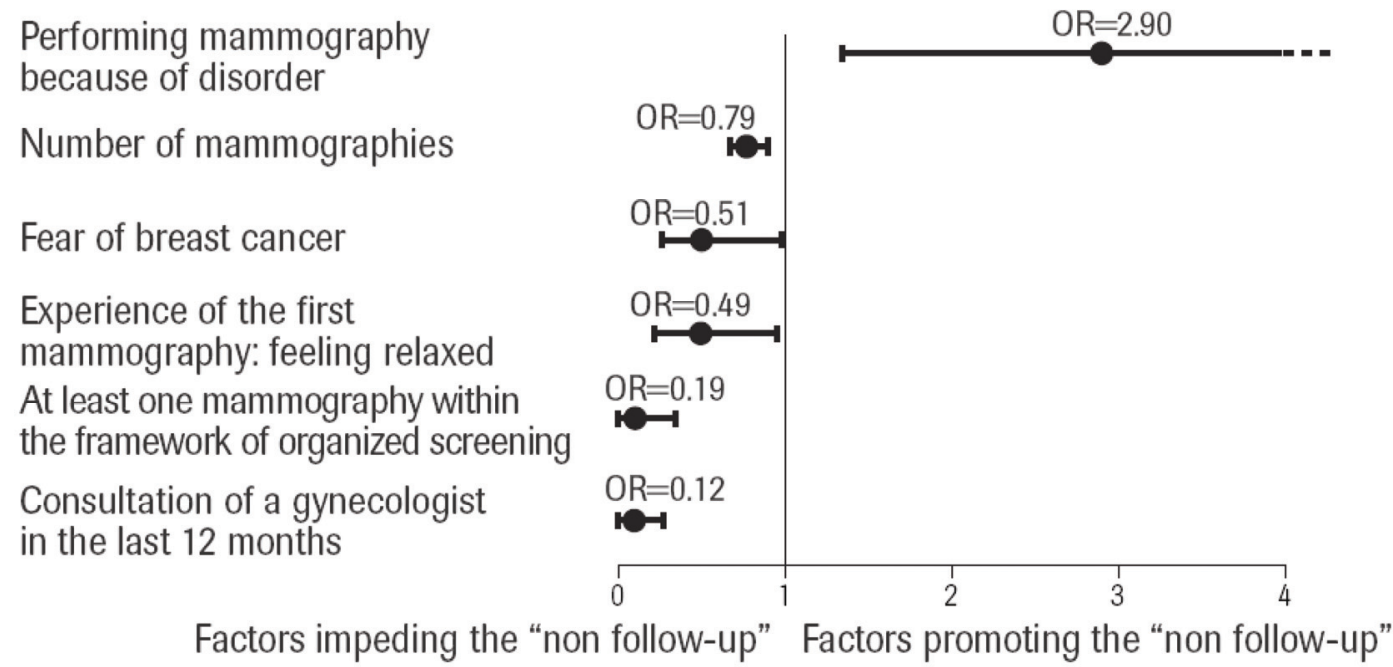

\begin{abstract}
Note: The following variables were tested in the multivariate analysis: socio-demographic factors (younger than 65 years old, married / cohabitation, high socio-professional level), behaviors toward health care (mammography done due to symptoms, GP at the origin of first mammography, gynaecologist at the origin of first mammography, GP consultation within the last 12 months, gynaecologist consultation within the last 12 months), own perception of screening (feeling relaxed, feeling concerned, feeling motivated, screening result increase chance to cure, number of mammography), anxious factors (cancer anxiety, breast cancer anxiety, screening test anxiety), cancer in surrounding (all cancer, breast cancer).
\end{abstract}

Figure 5: Multivariate analysis of the reasons for performing or not breast cancer screening every second year.

\section{Survey among General Practitioners}

Of the 600 participating GPs, 68.6\% (412/600) systematically and $29.1 \% \quad(175 / 600)$ frequently recommended a mammography to their patients. No relationship was found between GPs' recommendation and the time of implementation of organized screening in their regions. Gender was the major factor linked with a variation of recommendation: $73.1 \%$ versus $65.4 \%$ among female and male physician systematically recommend a screening, respectively $(p=0.025)$. GPs' perceptions of the reasons for women's avoidance of the screening test were unwillingness to be aware of mammography results $(44.4 \%$ - 266/600) and the belief that mammography was painful $(52.5 \%$ - 315/600).

\section{Discussion}

This survey reports the proportion of subjects declaring to have undergone at least one mammography as a screening test and it does not report the actual incidence of subjects screened for breast cancer. It is likely that some of the reported screening tests were diagnostic tests related to clinical symptoms.

There is a bias towards underestimation of the time since the last examination. It is established that screening rates self-reported over a fixed past period of time are higher than of the true rates $[7,8]$. Subjects commonly overestimate their compliance with recommendations $[9,10]$. Nevertheless, self-reported screening behaviors are generally fairly accurate, and many publications rely upon them $[11,12,13]$.

The main result of the EDIFICE survey is the high rate of women's attendance at mammography screening [14]. The main characteristics of women who never performed a screening mammography pointed out factors related to an isolated living status. It may be possible that the remaining $7.5 \%(38 / 507)$ who do not declare performing breast cancer screening represent an irreducible proportion. Those results clear out numerous beliefs and a priori concerning commitment and resistance for cancer screening [15]. Fear of cancer diagnosis, unwillingness to be aware of mammography results, belief that mammography was painful, unawareness of screening benefit, etc... appears to be unrelated with the realization of a screening mammography $[16,17]$. Nonetheless, the lower proportion of women aged between 50 and 54 years old who had done a mammography point out delayed adhesion during the first years of screening. This point suggests the need to reinforce the communication in this subset.

Besides, a large number (54.59\% - 422/773) of women had performed a screening mammography before 50 years old. One can consider that no issue seems to emerge among younger women $(<50$ years old) concerning an agreement with an early systematic screening plan. The public health benefit of such 
extended screening plan is debatable; nonetheless this study point out the possibility to obtain the adhesion of the population if a need for an earlier screening program should emerge.

The EDIFICE survey pointed out that systematic and organized screening was associated in the regularity and so efficacy, of screening tests for breast cancer. A subset of $20 \%$ had declared to not perform the screening test with the optimal recommended compliance. The generalization in France since 2003 of systematic organized screening is the first step to improve this situation, knowing the role of organized screening test in regard to regularity. One can consider fruitful to develop some efforts in terms of communication with the aim to reduce this proportion of delayed screening test. GPs and gynecologist appeared to be key actors in heightening public awareness and they could be the target of a communication plan to improve this issue.

In conclusion, this study clears out numerous beliefs and a priori concerning commitment and resistance for breast cancer screening. Authorities should take into account that cancer diagnosis fear is not an issue to perform a screening test, as commonly believe. Edifice survey points out that a national organization with a major GPs and gynecologist involvement are key success factors to achieve an efficient coverage based on a biannual rhythm.

\section{Conflict of interest}

The authors have declared that no conflict of interest exists.

\section{References}

1. Smith RA, Saslow D, Sawyer KA, et al. American Cancer Society guidelines for breast cancer screening: update 2003. CA Cancer J Clin 2003; 53:141-69.

2. Gillot D. L'annonce du plan cancer. Ministere de la Santé, 2000.

3. Eisinger F, Blay JY, Morere JF, et al. Cancer screening in France: subjects' and physicians' attitudes. Cancer Causes Control, 2008; 19: 431-434.

4. Deville J. A Theory of Quota Surveys. Survey Methodology 1991; 17:163 - 181.

5. Deville J, Särndal C, Sautory O. Generalized raking procedures in survey sampling. J Am Statist Assoc 1993; 88:1013-20.

6. Eisinger F, Cals L, Calazel-Benque A et al. Impact of organised programs on colorectal cancer screening. BMC Cancer 2008; 8: 104.

7. Aitken JF, Youl PH, Janda M, et al. Validity of self-reported skin screening histories. Am J Epidemiol 2004; 159:1098-105.

8. Gordon NP, Hiatt RA, Lampert DI. Concordance of self-reported data and medical record audit for six cancer screening procedures. Journal of the National Cancer Institute 1993; 85:566-70.

9. Hiatt RA, Perez-Stable EJ, Quesenberry CJr., et al. Agreement between self-reported early cancer detection practices and medical audits among Hispanic and non-Hispanic white health plan members in northern California. Prev Med 1995; 24:278-85.

10. Tsubono Y, Fukao A, Hisamichi S, et al. Accuracy of self-report for stomach cancer screening. J Clin Epidemiol 1994; 47:977-81.
11. Baier M, Calonge N, Cutter G, et al. Validity of self-reported colorectal cancer screening behavior. Cancer Epidemiol Biomarkers Prev 2000; 9:229-32.

12. Etzi S, Lane DS, Grimson R. The use of mammography vans by low-income women: the accuracy of self-reports. Am J Public Health 1994; 84:107-9.

13. Jordan TR, Price JH, King KA, et al. The validity of male patients' self-reports regarding prostate cancer screening. Prev Med 1999; 28:297-303.

14. Breen N, Wagener DK, Brown ML, et al. Progress in cancer screening over a decade: results of cancer screening from the 1987, 1992, and 1998 National Health Interview Surveys. J Natl Cancer Inst 2001; 93:1704-13.

15. Caplan LS, Helzlsouer KJ, Shapiro S, et al. Reasons for delay in breast cancer diagnosis. Preventive Medicine 1996; 25:218-24.

16. Denhaerynck K, Lesaffre E, Baele J, et al. Mammography screening attendance: meta-analysis of the effect of direct-contact invitation. Am J Prev Med 2003; 25:195-203.

17. Lerman C, Daly M, Sands C, et al. Mammography adherence and psychological distress among women at risk for breast cancer. J Natl Cancer Inst 1993; 85:1074-80. 